\title{
THE
}

\section{Noise level correlates with manatee use of foraging habitats}

Jennifer L. Miksis-Olds

University of Rhode Island

Percy L. Donaghay

University of Rhode Island, donaghay@uri.edu

James H. Miller

University of Rhode Island, miller@uri.edu

Peter L. Tyack

Jeffrey A. Nystuen

Follow this and additional works at: https://digitalcommons.uri.edu/gsofacpubs

Terms of Use

All rights reserved under copyright.

\section{Citation/Publisher Attribution}

Miksis-Olds, J. L., Donaghay, P. L., Miller, J. H., Tyack, P. L., \& Nystuen, J. A. (2007). Noise level correlates with manatee use of foraging habitats. The Journal of the Acoustical Society of America, 121(5), 3011-3020. doi: 10.1121/1.2713555

Available at: https://doi.org/10.1121/1.2713555

This Article is brought to you for free and open access by the Graduate School of Oceanography at DigitalCommons@URI. It has been accepted for inclusion in Graduate School of Oceanography Faculty Publications by an authorized administrator of DigitalCommons@URI. For more information, please contact digitalcommons-group@uri.edu. 


\section{Noise level correlates with manatee use of foraging habitats}

Jennifer L. Miksis-Olds, Percy L. Donaghay, James H. Miller, Peter L. Tyack, and Jeffrey A. Nystuen

Citation: The Journal of the Acoustical Society of America 121, 3011 (2007); doi: 10.1121/1.2713555

View online: https://doi.org/10.1121/1.2713555

View Table of Contents: http://asa.scitation.org/toc/jas/121/5

Published by the Acoustical Society of America

\section{Articles you may be interested in}

Manatee (Trichechus manatus) vocalization usage in relation to environmental noise levels

The Journal of the Acoustical Society of America 125, 1806 (2009); 10.1121/1.3068455

Transmission loss in manatee habitats

The Journal of the Acoustical Society of America 120, 2320 (2006); 10.1121/1.2258832

The underwater audiogram of the West Indian manatee (Trichechus manatus)

The Journal of the Acoustical Society of America 105, 3575 (1999); 10.1121/1.424681

Intraspecific and geographic variation of West Indian manatee (Trichechus manatus spp.) vocalizations (L)

The Journal of the Acoustical Society of America 114, 66 (2003); 10.1121/1.1582862

Determination of West Indian manatee vocalization levels and rate

The Journal of the Acoustical Society of America 115, 422 (2004); 10.1121/1.1635839

Low-frequency vocalizations in the Florida manatee (Trichechus manatus latirostris)

The Journal of the Acoustical Society of America 114, 2414 (2003); 10.1121/1.4778576 


\title{
Noise level correlates with manatee use of foraging habitats
}

\author{
Jennifer L. Miksis-Olds ${ }^{a)}$ and Percy L. Donaghay \\ Graduate School of Oceanography, University of Rhode Island, Narragansett, Rhode Island 02882 \\ James H. Miller \\ Department of Ocean Engineering \& Graduate School of Oceanography, University of Rhode Island, \\ Narragansett, Rhode Island 02882
}

Peter L. Tyack

Woods Hole Oceanographic Institution, Woods Hole, Massachusetts 02543

Jeffrey A. Nystuen

Applied Physics Laboratory, University of Washington, 1013 NE 40th Street, Box 355640, Seattle, Washington 98105

(Received 1 September 2006; revised 8 January 2007; accepted 3 February 2007)

\begin{abstract}
The introduction of anthropogenic sound to coastal waters is a negative side effect of population growth. As noise from boats, marine construction, and coastal dredging increases, environmental and behavioral monitoring is needed to directly assess the effect these phenomena have on marine animals. Acoustic recordings, providing information on ambient noise levels and transient noise sources, were made in two manatee habitats: grassbeds and dredged habitats. Recordings were made over two 6-month periods from April to September in 2003 and 2004. Noise levels were calculated in one-third octave bands at nine center frequencies ranging from $250 \mathrm{~Hz}$ to $64 \mathrm{kHz}$. Manatee habitat usage, as a function of noise level, was examined during four time periods: morning, noon, afternoon, and night. Analysis of sightings data in a variety of grassbeds of equal species composition and density indicate that manatees select grassbeds with lower ambient noise for frequencies below $1 \mathrm{kHz}$. Additionally, grassbed usage was negatively correlated with concentrated boat presence in the morning hours; no correlation was observed during noon and afternoon hours. This suggests that morning boat presence and its associated noise may affect the use of foraging habitat on a daily time scale. (c) 2007 Acoustical Society of America. [DOI: 10.1121/1.2713555]
\end{abstract}

PACS number(s): 43.80.Nd [WWA]

Pages: 3011-3020

\section{INTRODUCTION}

Florida manatees live in shallow coastal habitats that typically range from $\frac{1}{2} \mathrm{~m}$ to approximately $10 \mathrm{~m}$ in depth. The deepest portions of the habitat are utilized most often during travel from one site to another and occur in dredged channels such as the Intracoastal Waterway, open bay, and open ocean areas (Koelsch, 1997). When manatees are not traveling, they spend the majority of their time in the shallower waters of seagrass beds, sand bars, and secluded dredged habitats (Marine Mammal Commission, 1986). To better understand how noise may affect habitat usage in manatees, it is necessary to quantify ambient noise levels in their shallow water habitats.

Manatees are thought to rely upon sound for long range communication (Sousa-Lima et al., 2002). Because sound has the potential to travel long distances in water, it provides a reliable way for manatees to communicate beyond visual range in murky coastal waters. Other types of environmental sound signals, such as the breaking of surface waves on seawalls and land, can aid in navigation, whereas sound produced from watercraft can warn of an approaching vessel.

\footnotetext{
${ }^{a)}$ Current affiliation: School for Marine and Science Technology, University of Massachusetts Dartmouth, 838 S. Rodney French Blvd., New Bedford, MA 02744. Electronic mail: jmiksis@umassd.edu
}

The issue of how sound travels in the shallow waters of manatee habitats has recently become a topic of heightened interest because of the risk of collision between manatees and boats. The question of whether or not manatees can hear boats approaching in enough time to swim to safety is a matter of active debate. Understanding more about the noise levels to which manatees are exposed will not only contribute to answering the question of whether manatees can hear boats approaching, but it will also provide information on how the natural communication system of manatees may be impacted by rising levels of background noise and/or transient noise sources in their habitats.

An acoustic signal can be only detected when the sound intensity level of the signal exceeds the auditory threshold of the individual receiving the sound and is greater than the level of ambient noise over the bandwidth of hearing at similar frequencies. The lower the background noise, the farther a sound signal will travel before its level diminishes below the background noise level (Richardson et al., 1995). The effective range of communication, or range within which the information contained in signal is successfully transmitted to a receiver, depends on the ambient noise levels, acoustic propagation loss characteristics, and frequency and amplitude of the signals being transmitted to the receiver by the producer. Higher frequencies typically have a higher attenuation than lower frequencies, but in very shallow grassbed 
habitats the most efficient sound propagation occurs in the range of 2-20 kHz (Miksis-Olds and Miller, 2006). This occurs because low frequency sound wavelengths are larger than the water depth, resulting in quick absorption by the sediments. The Lloyd mirror effect also contributes to a greater attenuation in the low frequency component of signals (Etter, 1996). Environmental parameters such as water depth, salinity, temperature, bottom type, and wind speed also affect sound absorption and attenuation. Consequently, sound transmission differs for varying wavelengths in different manatee habitats, and different habitat types therefore affect the range at which manatees can detect either conspecific vocalizations or approaching vessels. It is entirely possible that both environmental noise and transmission loss are so great in some areas that manatees cannot detect boats until they are only a few tens of meters away. Manatees have been shown to utilize grassbeds with higher transmission loss characteristics more often than grassbed sites with lower levels of transmission loss (Miksis-Olds and Miller, 2006). High transmission loss compounded by high levels of ambient noise in grassbeds greatly diminishes the likelihood of detecting an approaching watercraft while it is still in the distance. Measurements of ambient noise levels associated with this study provide details to address whether or not this is a common circumstance.

The probability of detecting signals of interest, such as conspecific vocalizations, can also be reduced by masking from other acoustic signals in the environment. Masking, or the obscuring of sounds of interest by interfering sounds at similar frequencies, may hamper an animal's ability to detect a sound signal even when that signal is above the absolute hearing threshold (Richardson et al., 1995). The potential masking by high levels of human generated noise, as well as the cacophony of sounds manatees naturally encounter, provides a constant obstacle to effective vocal communication and the perception of other biologically significant signals. The level of masking is mainly due to noise at frequencies near the signal frequency of interest. Noise at frequencies outside this masking band has little influence on the detection of a signal unless the noise level is very high (Kryter, 1985; Richardson et al., 1995). From the viewpoint of a manatee, any signal of interest must overcome not only absorption and attenuation, but also masking by background noise and a myriad of broadband and narrow-band sounds. Ambient noise is environmental background noise that is generally unwanted sound that clutters and masks other sounds of interest (Richardson et al., 1995). Ambient noise has components that can be continuous or transient, broadband or tonal, directional or omnidirectional. Some of the major sound components in manatee habitats include high levels of noise due to wind and waves (broadband), watercraft (broadband), snapping shrimp (broadband), and fish and marine mammal vocalizations (broadband and narrow band).

With a firm grasp on both environmental noise and transmission loss in a specific habitat at a particular time, it becomes possible to begin to address questions of the range at which a signal can be detected. As a rule of thumb, a signal must be louder than the background noise level at similar frequencies in order for it to be detected. Conse- quently, a signal with a high source level and low amount of transmission loss may or may not be detected a mere $100 \mathrm{~m}$ away depending on how noisy the environment is. The ambient noise levels in coastal waters, bays, and harbors are subject to wider variations than the deep-water ambient noise, and coastal marine mammals must cope with sources of noise that are highly variable in time, frequency, and space (Urick, 1983). The motivation behind this study was to determine if manatees perceive and react to changes in ambient noise levels. Manatee habitat usage was examined in relation to ambient noise levels.

\section{METHODS}

Noise recordings were made in two habitat types: seagrass beds and dredged habitats. Sampling sites consisted of 13 grassbeds (sites A, B, D, F, G, H, I, N, O, S, T, V, and X) and 11 dredged habitats (sites C, E, J, K, L, M, P, Q, R, U, W) in Sarasota Bay, FL. The letter designations for each site were assigned based on geographic location in Sarasota Bay starting near Mote Marine Laboratory and progressing in a counter-clockwise direction around the bay (Fig. 1). The site identifications in this study are consistent with previously published work at the same sites (Miksis-Olds and Miller, 2006). Sites were selected based on manatee presence identified from aerial survey data from 2000 to 2003. Aerial survey data were obtained from Mote Marine Laboratory, and details of the surveys, habitat definitions, site selection criteria, and site details are provided in Miksis-Olds and Miller (2006) and Gannon et al. (2007). Percent usage for each site is defined as the percentage of surveys that manatees were observed in a specific site over the 3-year survey period. In summary, percent usage in the selected grassbeds ranged from $5 \%$ to $79 \%$. Dredged habitat usage ranged from 5\% to $40 \%$ over the same period. The pattern of site usage was not observed to change considerably from year to year over the period of 2000-2003, so it was assumed that the same pattern continued in 2004.

The quality of each grassbed site in terms of manatee foraging was characterized as part of a previous study during the same time period (Miksis-Olds and Miller, 2006). Total seagrass coverage and individual seagrass species [turtle grass (Thalassia testudinum), manatee grass (Syringodium filiforme), and shoal grass (Halodule wrightii)] coverage varied widely among the 13 seagrass habitats sampled. MiksisOlds (2006) found no significant correlation between manatee grassbed usage and either total grass coverage, individual species coverage, or aerial pattern. For the parameters measured, usage was not shown to vary as a function of seagrass habitat quality in relation to density. This does not necessarily reflect patterns of usage in relation to other unmeasured parameters of seagrass quality such as percentage of cropped shoots, shoot age, plant weight, etc.

\section{A. 2003 acoustic recordings}

During the 2003 season, 5 to $10 \mathrm{~min}$ recordings were made at each site with a HTI-99-HF hydrophone with built-in preamplifier. This hydrophone had an operational frequency range of $2-125000 \mathrm{~Hz}$ and a sensitivity of 


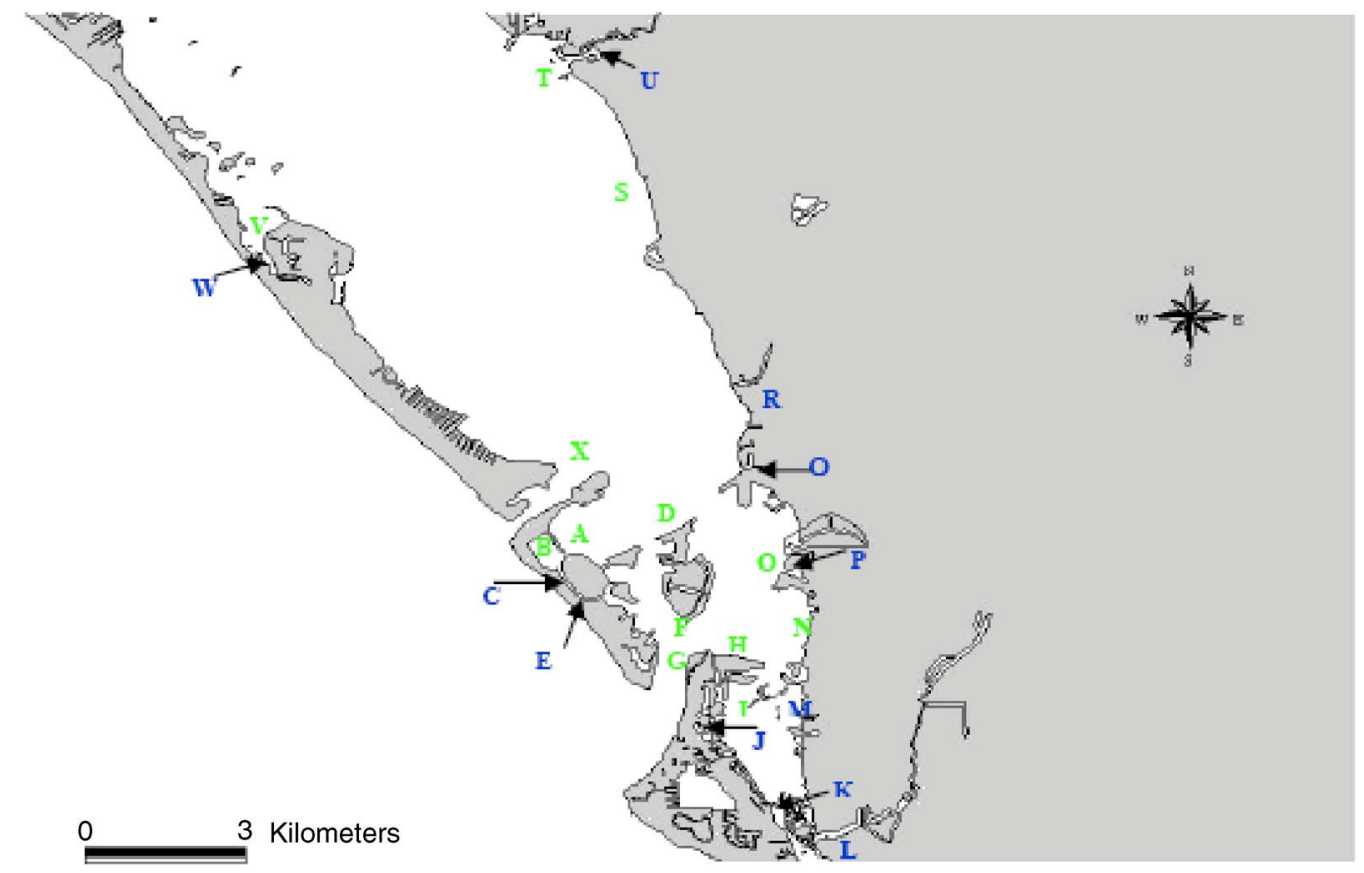

FIG. 1. (Color online) Site locations in Sarasota Bay.

$-178 \mathrm{~dB}$ re $1 \mathrm{~V} / \mu \mathrm{Pa}$. The analog signal was transferred to a Dell Inspiron 8110 via a National Instruments PCMCIA DAQ Card-6062E and digitized using the Chickadee Multichannel Recorder Version 1.9b software program. Recording system A refers to the entire recording chain composed of the components described above (hydrophone, DAQ card, and computer). All recordings were made at a sampling rate of $200 \mathrm{kHz}$.

Acoustic site sampling was conducted from April through September in 2003. Acoustic recordings of the 24 selected manatee habitats were made systematically one to two times per week, including weekends and holidays. All identified sites were sampled in succession over the period of a few hours on the same day. The time of day for sampling was rotated among three time periods: (1) morning (07:0010:30), (2) noon (10:30-14:00), and (3) afternoon (14:0017:30). The order of site recordings was based on geographical location. Each site was assigned a letter in a counterclockwise direction around the study area. The site at which the sampling regime began each week was selected randomly. Efforts were made to sample each site during each of the three time periods at least once per month (Fig 2). This

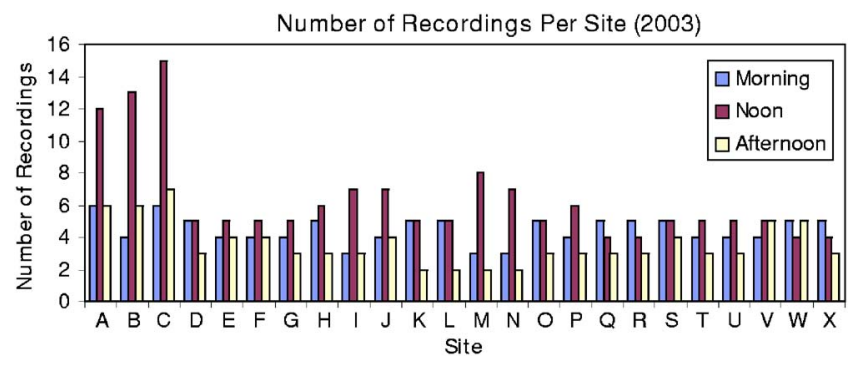

FIG. 2. (Color online) Number of recordings made at each site during each time period of the day. Grassbed sites are A, B, D, F, G, H, I, N, O, S, T, V, and X. Dredged habitat sites are C, E, J, K, L, M, P, Q, R, U, and W. was achieved during the morning and noon time periods, but fewer recordings were made during the afternoon time period due to late afternoon thunderstorms throughout the season. The above average sampling during the noon hours in sites $\mathrm{A}, \mathrm{B}$, and $\mathrm{C}$ is a by-product of where animals were most often encountered. Sites B and C were part of a manatee sanctuary, and site A was adjacent to the sanctuary. Noise recordings were taken during all animal sightings and focal animal follows performed as part of a collaborative field effort. These recordings were made in addition to days devoted strictly to acoustic site sampling. In total, 395 recordings were made across the 24 sites in 2003 .

\section{B. 2004 acoustic recordings}

In 2004, a different method for recording ambient noise was implemented. The goal of this sampling regime was to record noise levels in a single site over a longer consecutive period of time compared to 2003 recordings. This sampling was designed to provide better sampling of diurnal noise patterns. A passive acoustic listening (PAL) buoy was deployed for 3-4 days at each site. Each deployment included a minimum of two weekdays and one weekend day. This system consisted of a bottom mounted hydrophone system with a low-noise broadband hydrophone $(100 \mathrm{~Hz}$ to $50 \mathrm{kHz})$, electronic filter and two-stage amplifier, TT8 computer processor with $100 \mathrm{kHz}$ A/D sampler, 50 Mbyte memory card, and 51 amp-hour battery package (Nystuen, 2004). This system is referred to as recording system B.

The PAL buoy was programmed to power on and sample at 10-min intervals. The 10-min sampling interval was selected in order to preserve the battery pack over the field season and to conserve data storage space. Within each sampling interval, four $10-\mathrm{ms}$ time series were sampled at 5 -s intervals over a 20 -s time period. This sampling protocol was 
TABLE I. Average one-third octave noise levels in grassbeds (GB) $(n=13)$ and dredged (DB) habitats $(n=11)$ as a function of time of day in 2003, morning (7:00-10:30), noon hours (10:30-14:00), afternoon (14:00-17:30). The range of average site levels is presented in parentheses.

\begin{tabular}{|c|c|c|c|c|c|c|c|c|c|c|}
\hline \multirow[b]{2}{*}{$\begin{array}{c}\text { Time of } \\
\text { day }\end{array}$} & \multirow[b]{2}{*}{ Habitat } & \multicolumn{9}{|c|}{ Frequency } \\
\hline & & $250 \mathrm{~Hz}$ & $500 \mathrm{~Hz}$ & $1 \mathrm{kHz}$ & $2 \mathrm{kHz}$ & $4 \mathrm{kHz}$ & $8 \mathrm{kHz}$ & $16 \mathrm{kHz}$ & $32 \mathrm{kHz}$ & $64 \mathrm{kHz}$ \\
\hline \multirow[t]{2}{*}{ Morning } & GB & $68(52-80)$ & $68(49-80)$ & $68(54-80)$ & $67(47-79)$ & $66(47-79)$ & $67(47-79)$ & $68(47-79)$ & $68(47-79)$ & $67(47-79)$ \\
\hline & DB & $49(37-67)$ & $50(38-67)$ & $50(37-67)$ & $51(37-69)$ & $58(37-83)$ & 64 (37-91) & 65 (37-91) & $63(38-86)$ & $59(39-82)$ \\
\hline \multirow[t]{2}{*}{ Noon } & GB & 74 (61-96) & $74(61-95)$ & $74(60-95)$ & 73 (56-94) & 73 (56-94) & 73 (57-94) & 74 (57-95) & $73(56-95)$ & $73(56-95)$ \\
\hline & DB & $55(47-74)$ & $55(46-74)$ & $55(44-73)$ & $55(43-73)$ & $60(43-78)$ & $65(43-87)$ & $66(44-85)$ & $64(44-80)$ & $62(44-76)$ \\
\hline \multirow[t]{2}{*}{ Afternoon } & GB & $79(61-92)$ & $80(64-91)$ & $79(66-91)$ & $78(61-91)$ & $77(58-91)$ & 77 (57-91) & $77(58-91)$ & $77(58-91)$ & $77(58-91)$ \\
\hline & DB & $57(46-79)$ & $57(47-79)$ & $58(48-79)$ & $57(46-78)$ & $58(45-79)$ & $63(45-80)$ & $63(46-81)$ & $61(46-80)$ & $60(46-79)$ \\
\hline
\end{tabular}

internally hardwired. A 1024-point fast Fourier transform (FFT) $(0-50 \mathrm{kHz})$ was then performed on the time series to generate power spectra. The power spectral density (psd) curves for each 10 -ms sample were then processed to identify sound sources present by comparison to stored psd curves of known sources. Data were stored as $200-\mathrm{Hz}$ band averages in $0.1-\mathrm{dB}$ resolution from 0 to $3 \mathrm{kHz}$, and $1-\mathrm{kHz}$ band averages thereafter to conserve file space. If any of the four individual psd curves did not trigger a modified sampling regime, the spectra were averaged, stored as a single spectrum for the sampling period, and the instrument returned to "sleep" mode. However, if one of two criteria were met during the analysis of the four psd curves, the sampling regime would be modified to a 2-min sampling interval instead of 10 . The first criterion was designed to reject transients. If one of the four spectra differed by more than $20 \mathrm{~dB}$, indicating a transient source, the instrument was programmed to discard the first sampling set and modify its sampling regime. If transients were detected in the three consecutive sampling sets, the four psd curves of the last set were stored and the instrument returned to "sleep" mode. This criterion selected against the inclusion of transient signals, such as clicks from snapping shrimp, in the acoustic record. The second criterion was the detection of sound sources of interest, which for this study included boat traffic and rain. A modified sampling regime was triggered if the spectra resembled previously stored spectra indicating specific sound sources, and all four spectra were stored for each sampling set. Sampling continued at the 2-min interval until the source was no longer present.

\section{Noise level analysis}

In 2003, noise levels for each site recording were determined for one-third octave bands at nine center frequencies: $250 \mathrm{~Hz}, 500 \mathrm{~Hz}, 1 \mathrm{kHz}, 2 \mathrm{kHz}, 4 \mathrm{kHz}, 8 \mathrm{kHz}, 16 \mathrm{kHz}$, $32 \mathrm{kHz}$, and $64 \mathrm{kHz}$. A one-third octave bandpass filter with $30-\mathrm{dB}$ side lobes was created for each of the specified frequencies. One-third octave noise levels were calculated at 4 -s intervals and then averaged over the duration of the 5-10-min site recording to produce an average one-third octave noise level at a specified center frequency at a particular time and day. System noise for recording system A was obtained by suspending the hydrophone in-air and recording in a quiet room. All gain settings were identical to those used in the field. The electronic noise floor of recording system A was at least $11 \mathrm{~dB}$ below the minimum recorded ambient noise level for all one-third octave bands.

Noise levels from each 2004 deployment were calculated for one-third octave bands at eight center frequencies. The stored psd center frequencies sampled with the PAL buoy were not at precise octave intervals, so the center frequencies closest to those analyzed in 2003 were selected: $300 \mathrm{~Hz}, \quad 500 \mathrm{~Hz}, \quad 1.1 \mathrm{kHz}, \quad 2.1 \mathrm{kHz}, \quad 4.6 \mathrm{kHz}, \quad 8.5 \mathrm{kHz}$, $16.3 \mathrm{kHz}$, and $31.9 \mathrm{kHz}$. For all frequencies, the analyzed bandwidth included the center frequencies measured in 2003. An average noise level within each of four time periods was calculated: (1) morning (07:00-10:30), (2) noon (10:3014:00), (3) afternoon (14:00-17:30), and (4) night (17:3024:00). The time periods were consistent with those used in 2003 , with the addition of a fourth nighttime period. The electronic noise floor of recording system $\mathrm{B}$ was at least $8 \mathrm{~dB}$ below the minimum recorded ambient noise level for all one-third octave bands.

\section{RESULTS}

\section{A. 2003 ambient noise levels}

Ambient noise was analyzed in nine one-third octave bands spanning $250 \mathrm{~Hz}$ to $64 \mathrm{kHz}$ during three time periods of the day. Analyses were performed to examine patterns both within and across the two habitat types. Overall noise patterns in the Sarasota Bay area differed between grassbed and dredged habitats (Table I). A repeated measure twofactor (habitat type $\times$ time of day) multivariate ANOVA showed that there was a significant habitat interaction for all frequencies except $16 \mathrm{kHz}$ at the $5 \%$ significance level (16 kHz: $F=4.13, p=0.054)$. Grassbeds were significantly louder than dredged habitats (average $14 \mathrm{~dB}$ louder across observed one-third octave bands). There was also a significant time of day interaction within habitat type, but not across habitat types. Unplanned, or posthoc, multiple comparisons using the least significant difference showed that for all frequencies, noise in the grassbeds was significantly louder in the noon and afternoon compared to morning time periods. In the dredged habitats, noise in the morning was significantly lower than noise in the afternoon for frequencies below $2 \mathrm{kHz}$. Above $2 \mathrm{kHz}$, noise in the morning tended to be the loudest. 
Noise levels also differed significantly across the two habitat types, but only at particular times of day (Fig. 3 and Table I). Posthoc multiple comparisons of the repeated measure two-factor, multivariate ANOVA showed a significant habitat $\times$ time of day interaction for frequencies $4 \mathrm{kHz}$ and higher $(3.93<F<5.49,0.03<p<0.007)$. The emerging pattern was that for frequencies $4 \mathrm{kHz}$ and above, a significant difference existed between the average noise level in the grassbeds and dredged habitats in the afternoon, with the grassbeds having a greater average noise level in the late afternoon. For frequencies below $4 \mathrm{kHz}$, there was no significant habitat $\times$ time of day interaction.

Regression analyses performed within each habitat type and each frequency band showed a significant correlation between usage by manatees and one-third octave band noise in grassbeds at all frequencies during the morning and afternoon time periods (Fig. 4 and Table II). Sites that were used more heavily by manatees tended to have lower levels of noise. For all significant regressions, $R$-squared values ranged from 0.41 to 0.49 in the morning and 0.56 to 0.71 in the afternoon. No significant relationship was observed for grassbeds during the noon hours or for the dredged habitats during any time period.

\section{B. 2004 ambient noise levels}

Ambient noise was analyzed at eight frequencies spanning $300 \mathrm{~Hz}$ to $32 \mathrm{kHz}$ during four time periods of the day to test for differences within and across grassbed and dredged habitats. Results from this sampling regime showed overall noise patterns in the Sarasota Bay area differed slightly between grassbed habitats and dredged habitats (Table III). A repeated measure two-factor (habitat type $\times$ time of day) multivariate ANOVA showed no habitat interaction across time periods of the day, so on average, grassbeds and dredged habitats had similar noise levels. However, there was a significant habitat type $\times$ time of day interaction for the lowest two frequencies measured: 250 and $500 \mathrm{~Hz}$ $(3.33<F<3.99,0.01<0.02)$. For these two cases, noise in the grassbeds was louder than in the dredged habitats during the morning.

Regression analyses were performed within each habitat type and at each frequency in order to determine if ambient noise level was correlated with manatee usage. Results showed a correlation between usage and noise in grassbeds at frequencies below $1 \mathrm{kHz}$ during the morning and afternoon time periods (Table IV). Correlations were also present in the grassbeds at noon for the lowest frequency and in the dredged basins at frequencies of $500 \mathrm{~Hz}$ and below in the morning and afternoon time periods. Sites that were used more heavily by manatees tended to have lower levels of noise. For all significant regressions at the $95 \%$ significance level, $R$-squared values ranged from 0.60 to 0.70 in the morning and 0.60 to 0.63 in the afternoon. No significant relationship at the $95 \%$ significance level was observed in either habitat at night or in the dredged habitats during the noon hours.

Results from 2003 and 2004 indicate that manatee usage is correlated with noise level in the grassbeds for the morn-
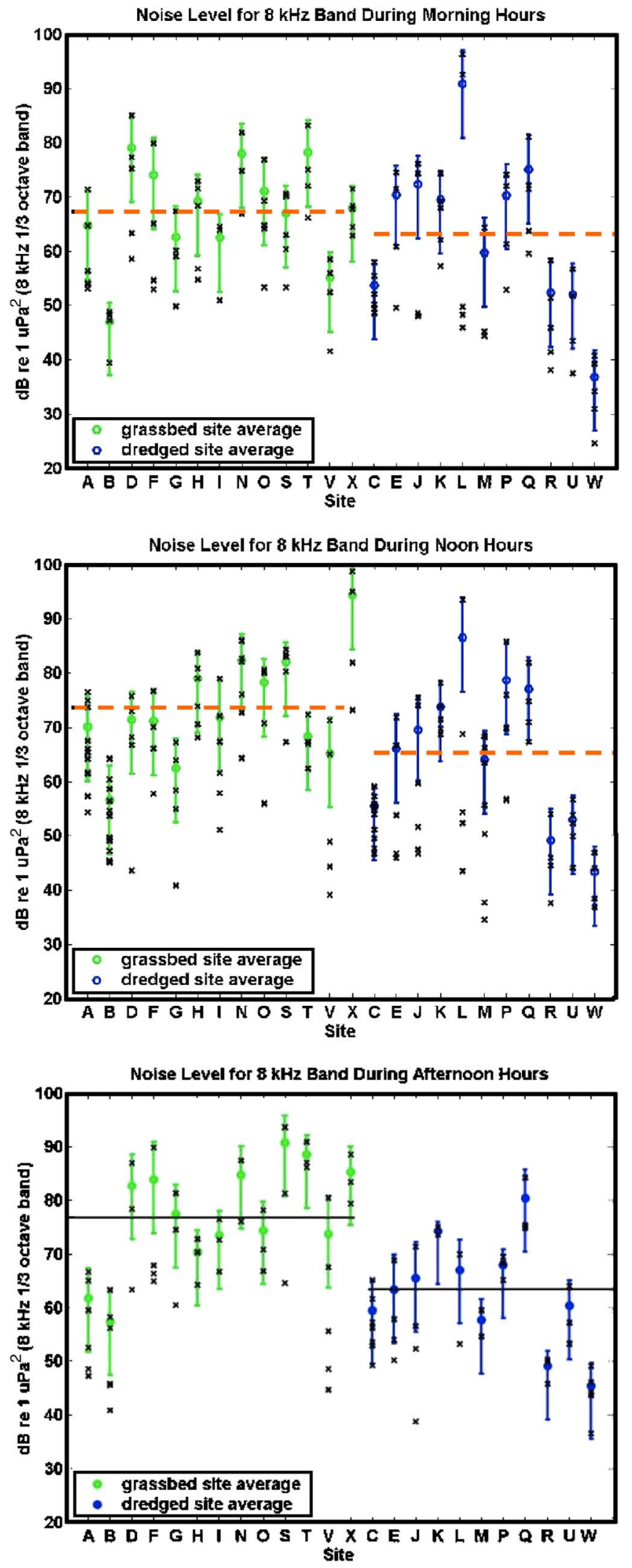

FIG. 3. (Color online) Noise levels in grassbeds and dredged habitats reported in one-third octave bands for $8 \mathrm{kHz}$ center frequency. Top panel shows noise during the morning (7:00-10:30), middle panel shows noise during the noon hours (10:30-14:00), and bottom panel shows noise during the afternoon hours (14:00-17:30). Each circle represents the average level in each site with corresponding error bars. Solid black lines indicate a significant difference in means between grassbed sites and dredged habitats. Dashed red lines represent means that did not differ significantly. 
32k Hz Noise Level as a Function of Morning Grassbed Usage

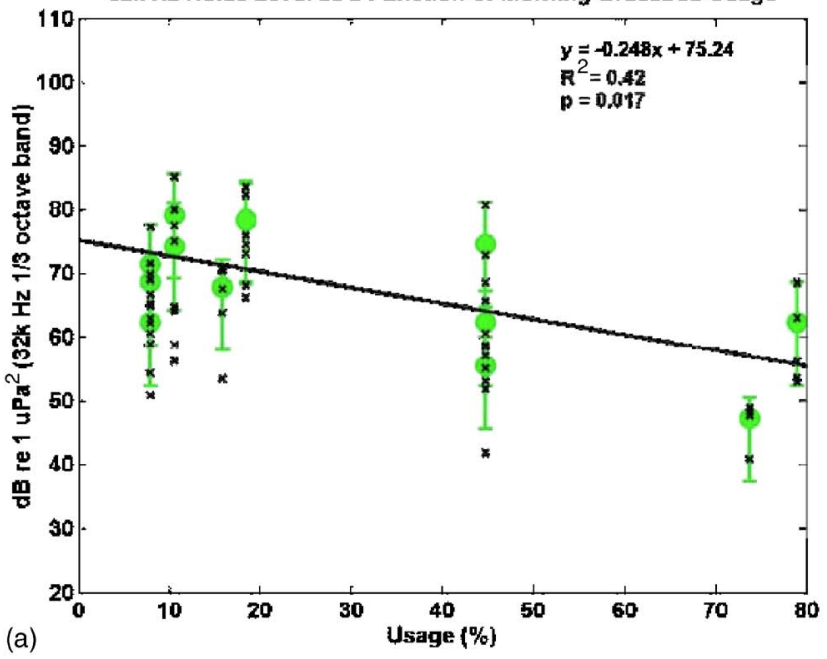

(a)

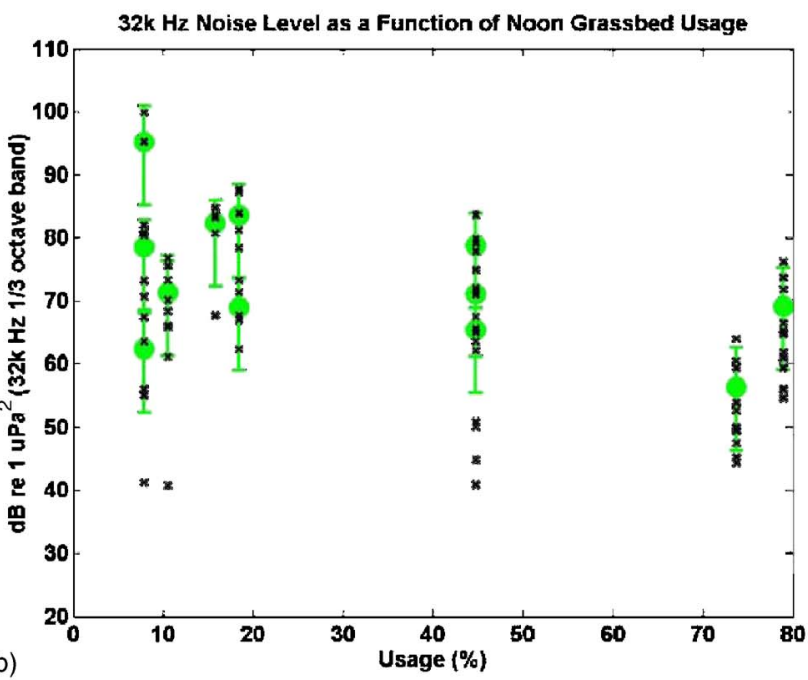

32k Hz Noise Level as a Function of Afternoon Grassbed Usage

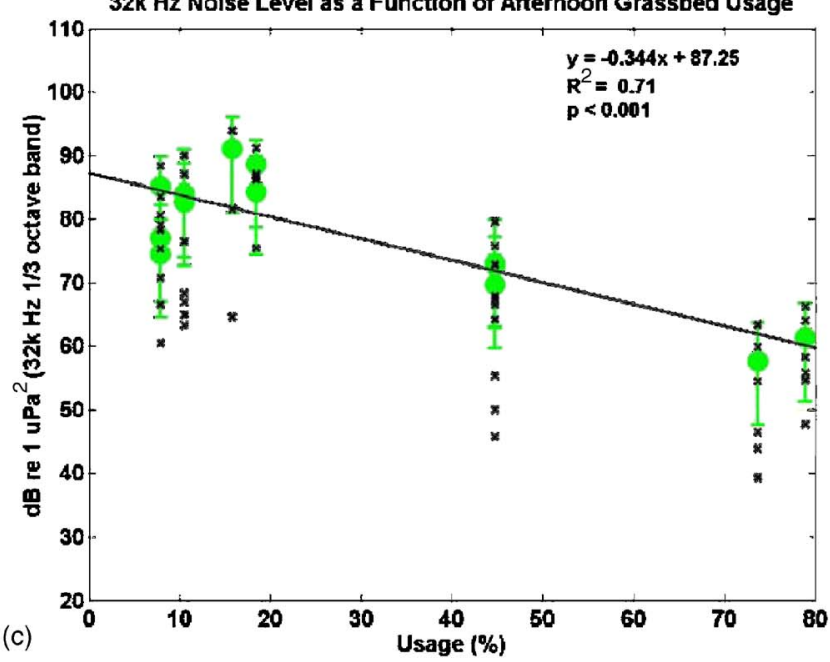

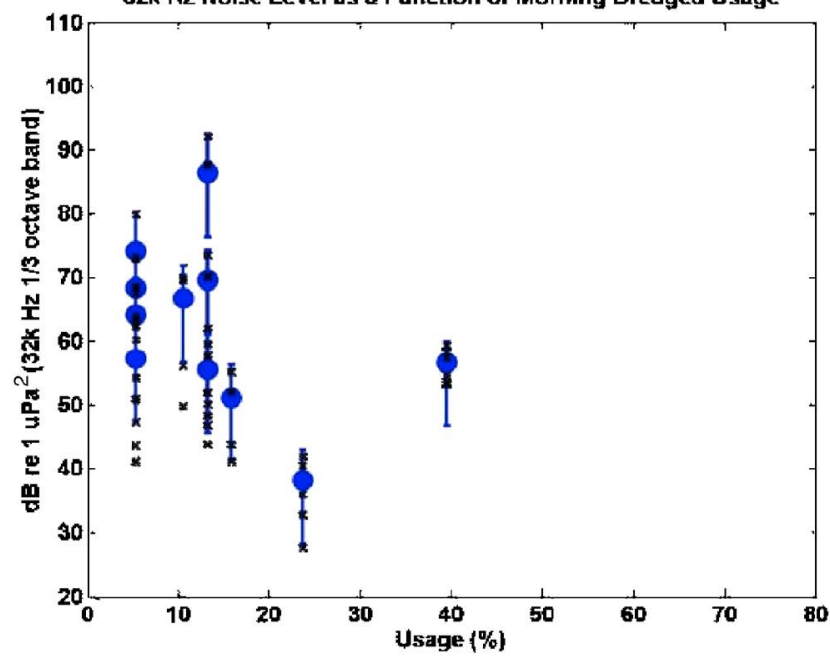
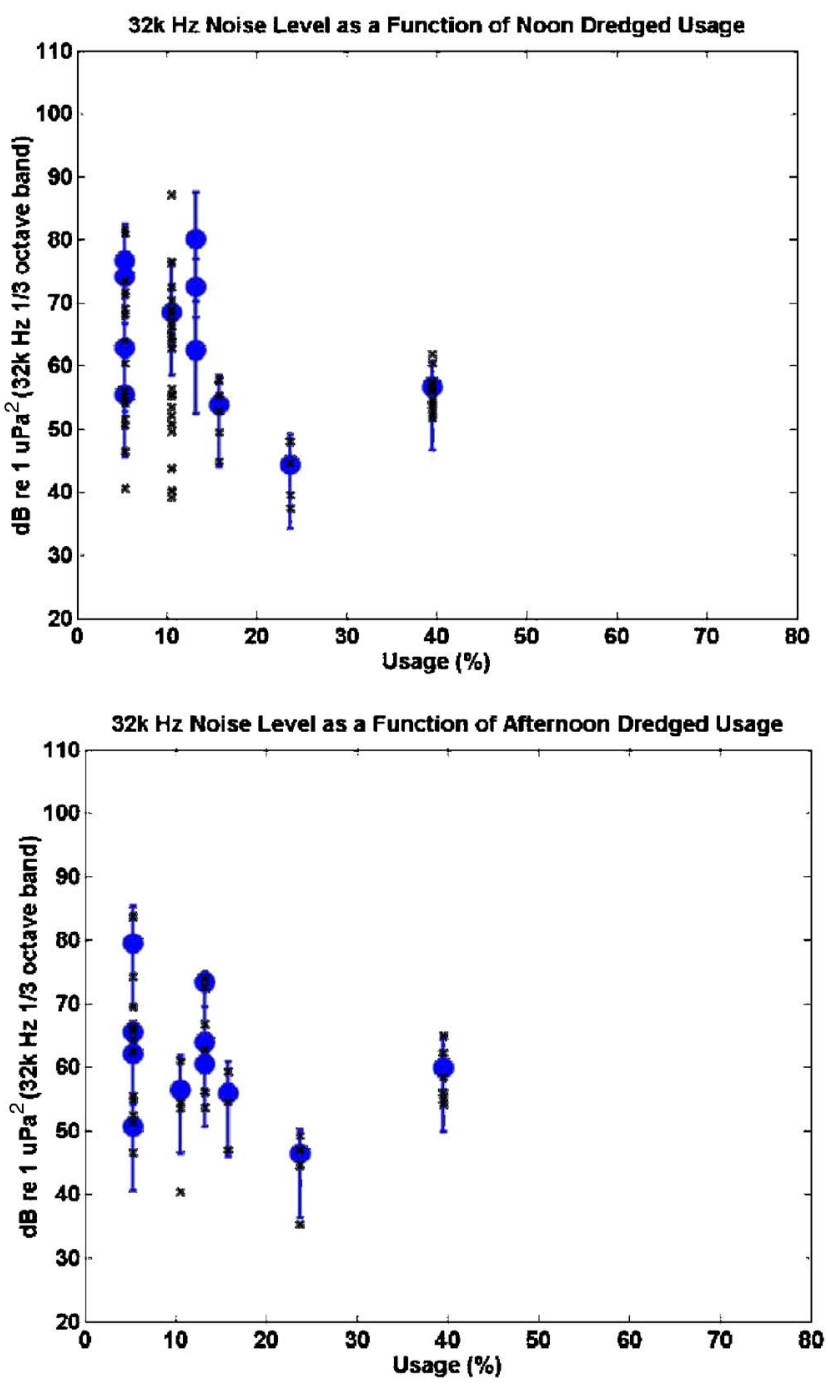

FIG. 4. (Color online) The $32 \mathrm{kHz}$ noise level during morning (a), noon (b), and afternoon (c) as a function of manatee site usage in grassbeds and dredged habitats. Each circle represents the average level in each site with corresponding error bars. The $x$ symbols represent individual measurements. The solid black line indicates a significant relationship at the $95 \%$ significance level.

ing and afternoon time periods. The results of both sampling methods overlap for the lowest two frequency categories (Tables II and IV). Areas that manatees used most tended to be quieter.

\section{2003 versus 2004}

An argument can be made that the observed differences in noise levels and corresponding usage correlations between 
TABLE II. Regression analysis $p$ values for ambient noise levels and usage comparisons at specified frequencies during three times of day in 2003. Italicized values show significant relationships.

\begin{tabular}{cccc}
\hline \hline Frequency & Morning & Noon & Afternoon \\
\hline & \multicolumn{2}{c}{ Grassbeds } & \\
$250 \mathrm{~Hz}$ & $\mathbf{0 . 0 0 8}$ & 0.1 & $<\boldsymbol{0 . 0 0 1}$ \\
$500 \mathrm{~Hz}$ & $\mathbf{0 . 0 1 9}$ & 0.14 & $\mathbf{0 . 0 0 1}$ \\
$1 \mathrm{kHz}$ & $\mathbf{0 . 0 0 7}$ & 0.12 & $\mathbf{0 . 0 0 3}$ \\
$2 \mathrm{kHz}$ & $\mathbf{0 . 0 0 6}$ & 0.1 & $<\boldsymbol{0 . 0 0 1}$ \\
$4 \mathrm{kHz}$ & $\mathbf{0 . 0 0 8}$ & 0.1 & $<\boldsymbol{0 . 0 0 1}$ \\
$8 \mathrm{kHz}$ & $\mathbf{0 . 0 1 7}$ & 0.11 & $<\boldsymbol{0 . 0 0 1}$ \\
$16 \mathrm{kHz}$ & $\mathbf{0 . 0 1 7}$ & 0.11 & $<\boldsymbol{0 . 0 0 1}$ \\
$32 \mathrm{kHz}$ & $\mathbf{0 . 0 1 7}$ & 0.09 & $<\boldsymbol{0 . 0 0 1}$ \\
$64 \mathrm{kHz}$ & $\mathbf{0 . 0 0 8}$ & 0.09 & $<\boldsymbol{0 . 0 0 1}$ \\
& Dredged habitats & 0.78 \\
$250 \mathrm{~Hz}$ & 0.31 & 0.31 & 0.26 \\
$500 \mathrm{~Hz}$ & 0.41 & 0.41 & 0.54 \\
$1 \mathrm{kHz}$ & 0.24 & 0.31 & 0.65 \\
$2 \mathrm{kHz}$ & 0.23 & 0.23 & 0.54 \\
$4 \mathrm{kHz}$ & 0.15 & 0.18 & 0.3 \\
$8 \mathrm{kHz}$ & 0.15 & 0.18 & 0.33 \\
$16 \mathrm{kHz}$ & 0.19 & 0.16 & 0.37 \\
$32 \mathrm{kHz}$ & 0.19 & 0.14 & 0.17 \\
$64 \mathrm{kHz}$ & 0.25 & & \\
\hline \hline
\end{tabular}

the two years were due to changes in noise characteristics instead of the different sampling techniques. Noise recordings obtained during all animal observations in 2004 were made with the same recording system (recording system A) used in 2003. Noise recordings utilizing recording system A in 2004 were limited to sites in which animals were commonly encountered (sites $\mathrm{A}, \mathrm{B}$, and $\mathrm{C}$ ). The ANOVA results showed that noise levels in these sites did not differ significantly between 2003 and 2004 (Table V). Based on these results, it can be assumed that the overall noise levels in the bay did not change significantly from 2003 to 2004.

\section{Boat noise}

The question of whether boats play a dominant role in the observed noise patterns can begin to be answered by analyzing the number of boats present in the vicinity of each site during the 2003 acoustic recordings. The number of boats passing within a $1-\mathrm{km}$ radius of the research vessel was
TABLE IV. Regression analysis $p$ values for ambient noise levels and usage comparisons at specified frequencies during four times of day in 2004. Italicized values show significant relationships.

\begin{tabular}{ccccc}
\hline \hline Frequency & Morning & Noon & Afternoon & Night \\
\hline & \multicolumn{5}{c}{ Grassbeds } \\
$250 \mathrm{~Hz}$ & $<0.001$ & 0.08 & 0.03 & 0.27 \\
$500 \mathrm{~Hz}$ & 0.01 & 0.13 & 0.05 & 0.94 \\
$1 \mathrm{kHz}$ & 0.05 & 0.12 & 0.19 & 0.88 \\
$2 \mathrm{kHz}$ & 0.41 & 0.5 & 0.43 & 0.53 \\
$4 \mathrm{kHz}$ & 0.51 & 0.39 & 0.44 & 0.47 \\
$8 \mathrm{kHz}$ & 0.4 & 0.54 & 0.58 & 0.44 \\
$16 \mathrm{kHz}$ & 0.23 & 0.51 & 0.46 & 0.3 \\
$32 \mathrm{kHz}$ & 0.24 & 0.52 & 0.62 & 0.43 \\
& & Dredged habitats & & \\
$250 \mathrm{~Hz}$ & $\mathbf{0 . 0 1}$ & 0.06 & $\mathbf{0 . 0 2}$ & 0.07 \\
$500 \mathrm{~Hz}$ & $\mathbf{0 . 0 3}$ & 0.12 & $\mathbf{0 . 0 4}$ & 0.14 \\
$1 \mathrm{kHz}$ & 0.37 & 0.56 & 0.21 & 0.16 \\
$2 \mathrm{kHz}$ & 0.64 & 0.25 & 0.16 & 0.2 \\
$4 \mathrm{kHz}$ & 0.52 & 0.22 & 0.11 & 0.24 \\
$8 \mathrm{kHz}$ & 0.59 & 0.14 & 0.16 & 0.27 \\
$16 \mathrm{kHz}$ & 0.26 & 0.19 & 0.14 & 0.18 \\
$32 \mathrm{kHz}$ & 0.46 & 0.28 & 0.3 & 0.3 \\
\hline \hline
\end{tabular}

documented during each acoustic recording in 2003. A 1-km radius was chosen because manatees have been shown to respond to approaching boats up to $1 \mathrm{~km}$ away (Nowacek et al., 2002). A set of single classification ANOVAs showed there was no significant difference in the average number of boats per site as a function of time of day in grassbeds or dredged habitat. However, there was a correlation at the $95 \%$ significance level between manatee grassbed usage and the average number of boats passing/5-min time period during the morning hours $\left(R^{2}=0.409, p=0.018\right)$ (Fig. 5). A detailed analysis of the corresponding noise levels showed a positive correlation between morning noise level and the average number of boats in grassbeds (Fig. 6). Linear regression showed a significant increase in grassbed noise level with an increase in boat presence during the morning hours for all frequencies examined (Table VI). There was no correlation between number of boats and manatee usage of grassbed sites during the noon or afternoon hours or in dredged habitats at any time of day.

TABLE III. Average noise levels in grassbeds and dredged habitats as a function of time of day obtained from PAL measurements in 2004. All noise level values are presented in $\mathrm{dB}$ re $1 \mu \mathrm{Pa}$. Ranges are presented in parentheses.

\begin{tabular}{|c|c|c|c|c|c|c|c|c|c|}
\hline \multirow{2}{*}{$\begin{array}{c}\text { Time of } \\
\text { day }\end{array}$} & \multirow[b]{2}{*}{ Habitat } & \multicolumn{8}{|c|}{ Frequency } \\
\hline & & $250 \mathrm{~Hz}$ & $500 \mathrm{~Hz}$ & $1 \mathrm{kHz}$ & $2 \mathrm{kHz}$ & $4 \mathrm{kHz}$ & $8 \mathrm{kHz}$ & $16 \mathrm{kHz}$ & $32 \mathrm{kHz}$ \\
\hline \multirow[t]{2}{*}{ Morning } & GB & $67(53-79)$ & $62(52-72)$ & $57(52-66)$ & $54(46-71)$ & $52(37-72)$ & $49(34-69)$ & $45(33-64)$ & $41(31-58)$ \\
\hline & DB & $65(57-76)$ & $60(53-71)$ & $58(51-69)$ & $55(41-73)$ & $54(40-71)$ & $49(37-64)$ & $46(33-58)$ & $42(31-52)$ \\
\hline \multirow[t]{2}{*}{ Noon } & GB & $69(56-81)$ & $63(57-74)$ & $57(44-64)$ & $55(43-68)$ & $53(43-66)$ & $48(41-68)$ & $45(36-62)$ & $41(32-57)$ \\
\hline & DB & $67(59-81)$ & $62(55-74)$ & $58(52-73)$ & $55(42-72)$ & $54(41-70)$ & $49(38-63)$ & $47(39-55)$ & $43(34-52)$ \\
\hline \multirow[t]{2}{*}{ Afternoon } & GB & $68(54-82)$ & $62(51-76)$ & $55(44-63)$ & $54(46-66)$ & $51(45-66)$ & $47(38-64)$ & $44(36-53)$ & $40(33-56)$ \\
\hline & DB & $67(57-81)$ & $62(54-73)$ & $58(51-68)$ & $55(44-68)$ & $53(40-65)$ & $49(38-65)$ & $47(35-66)$ & $43(33-65)$ \\
\hline \multirow[t]{2}{*}{ Night } & GB & $68(56-81)$ & $63(54-72)$ & $55(46-62)$ & $51(42-65)$ & $48(37-67)$ & $45(32-65)$ & $44(32-63)$ & $41(31-51)$ \\
\hline & DB & $68(58-79)$ & $62(55-70)$ & $60(54-63)$ & $57(45-65)$ & $54(40-65)$ & $50(37-60)$ & $47(35-56)$ & $43(33-50)$ \\
\hline
\end{tabular}


TABLE V. Average 1/3-octave band noise level comparisons for 2003 and 2004.

\begin{tabular}{lcccccccccc}
\hline \hline & & 250 & 500 & 1 & 2 & 4 & 8 & 16 \\
$\mathrm{~Hz}$ & $\mathrm{~Hz}$ & $\mathrm{kHz}$ & $\mathrm{kHz}$ & $\mathrm{kHz}$ & $\mathrm{kHz}$ & $\mathrm{kHz}$ \\
& & & & $\mathrm{kHz}$ & $\mathrm{kHz}$ \\
\hline \multirow{2}{*}{ Site A } & 2003 & 66 & 70 & 68 & 65 & 64 & 66 & 65 & 64 & 64 \\
& 2004 & 63 & 63 & 62 & 61 & 61 & 62 & 62 & 62 & 62 \\
Site B & 2003 & 58 & 58 & 60 & 55 & 53 & 54 & 54 & 54 & 54 \\
& 2004 & 54 & 55 & 53 & 53 & 52 & 53 & 53 & 53 & 53 \\
Site C & 2003 & 52 & 54 & 51 & 51 & 52 & 56 & 58 & 58 & 57 \\
& 2004 & 53 & 53 & 52 & 53 & 53 & 55 & 58 & 57 & 56 \\
\hline \hline
\end{tabular}

\section{DISCUSSION}

Manatees live in an acoustic environment that is highly variable in both space and time. Noise intensity level can change by orders of magnitude in a span of seconds. In general, grassbeds tended to be louder than dredged habitats due to the loud broadband noise produced by snapping shrimp (Alpheus and Synalpheus sp), which becomes stronger with decreasing depth (Camp et al., 1998; Richardson et al., 1995, Miksis-Olds, 2006). The noise level patterns, however, differed greatly between the two years due to the different sampling methods. In 2003, recordings were made with a single hydrophone and processed at a later date. Processing of the 2003 data included all sounds present in the environment without any special weighting or selection. Noise produced by snapping shrimp dominated the shallow habitat noise recordings in 2003; furthermore, the 2003 noise level analysis did not distinguish between the confounding factors of broadband shrimp noise and lower frequency anthropogenic noise. Noise recordings in 2004 were also made from a single hydrophone, but initial processing of the noise spectrum was done in real time. With this processing protocol, transients such as broadband signals produced by snapping shrimp were selected against, so the resulting noise recordings more accurately reflected patterns associated with low frequency anthropogenic noise as opposed to the loud biological signal of snapping shrimp.

This study benefited from the implementation of two different noise sampling techniques that allowed for the separation of confounding factors associated with the recordings in 2003. Filtering the transient signals out of the acoustic record in the 2004 data set essentially removed the broadband shrimp sounds, which allowed for the identification of

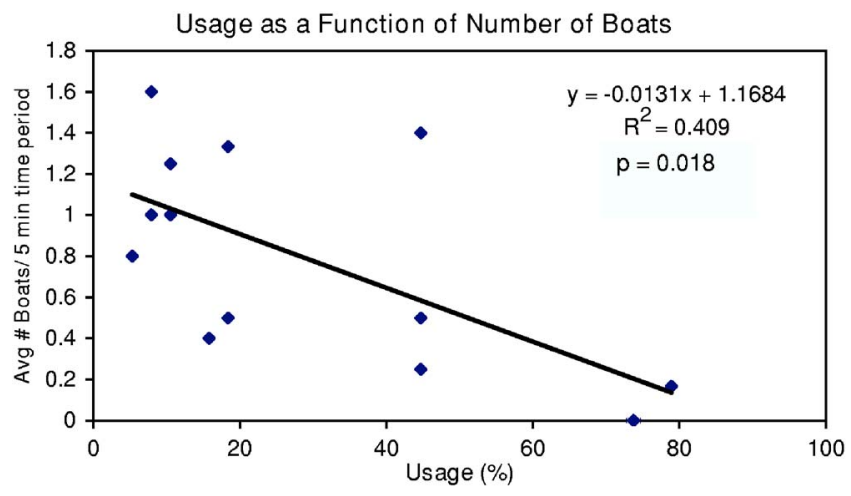

FIG. 5. (Color online) Manatee site usage as a function of boat presence in grassbeds.

3018 J. Acoust. Soc. Am., Vol. 121, No. 5, May 2007
TABLE VI. Linear regression statistics indicating a significant positive correlation between boat presence and noise level.

\begin{tabular}{cccc}
\hline \hline Frequency & $R^{2}$ & $F$ & $p$ value \\
\hline $250 \mathrm{~Hz}$ & 0.41 & 7.80 & 0.017 \\
$500 \mathrm{~Hz}$ & 0.32 & 5.29 & 0.041 \\
$1 \mathrm{kHz}$ & 0.36 & 6.22 & 0.030 \\
$2 \mathrm{kHz}$ & 0.37 & 6.36 & 0.028 \\
$4 \mathrm{kHz}$ & 0.36 & 6.09 & 0.031 \\
$8 \mathrm{kHz}$ & 0.36 & 6.08 & 0.031 \\
$16 \mathrm{kHz}$ & 0.37 & 6.54 & 0.027 \\
$32 \mathrm{kHz}$ & 0.43 & 8.28 & 0.015 \\
$64 \mathrm{kHz}$ & 0.35 & 7.42 & 0.020 \\
\hline \hline
\end{tabular}

patterns associated with lower energy, more narrow-band anthropogenic noise. Based on the analysis of habitat use and noise recordings in 2003, manatees select grassbed sites that have lower noise levels across a wide range of frequencies. The relationship between usage and noise, however, was only present during the morning and late afternoon time periods. Although snapping shrimp noise is constantly present, these time periods are associated with both sunrise and sunset, which happens to be linked with the small diurnal increase in activity that snapping shrimp exhibit at night (Albers, 1965; Au and Banks, 1998). The 2003 regression results suggest that manatees select the quietest grassbed sites during the peak times of snapping shrimp activity, which implies that manatees select grassbeds with less snapping shrimp noise. The 2004 recordings reduced the presence of the snapping shrimp noise, although they did exhibit a slight diurnal variation associated with this biologic noise source. The analysis of the 2004 data indicated that manatees selected grassbed sites that have less low frequency noise, which is most likely attributed to anthropogenic activity. The question of whether shrimp noise or anthropogenic noise is the major force behind the observed manatee distribution patterns cannot be answered conclusively with the current data, and the possibility remains that the presence or absence of snapping shrimp correlates with some aspect of habitat quality that was not measured. However, it is clear that noise is one factor that correlates with manatee habitat selection.

The current study builds upon previous transmission loss measurements conducted in the same sites of Sarasota, FL over the same time period. Miksis-Olds and Miller (2006) showed that grassbeds used most often by manatees had high levels of transmission loss above $2 \mathrm{kHz}$. However, it was noted that information pertaining to environmental noise levels in specific habitats is needed in order to more fully understand questions pertaining to manatee habitat selection and signal detection. By combining information about habitat usage in relation to transmission loss characteristics with daily noise patterns (both biologic and anthropogenic), an interesting two-part picture starts to emerge. Manatee usage of grassbed habitats was highly correlated with broadband noise, low frequency noise, and high frequency transmission loss. High-use grassbeds were areas of high transmission loss (frequencies $>2 \mathrm{kHz}$ ) and low broadband and low frequency noise (frequencies $<1 \mathrm{kHz}$ ). This creates a high-use environment where noise above $2 \mathrm{kHz}$ from sources outside the

Miksis-Olds et al.: Noise levels and manatee habitat use 


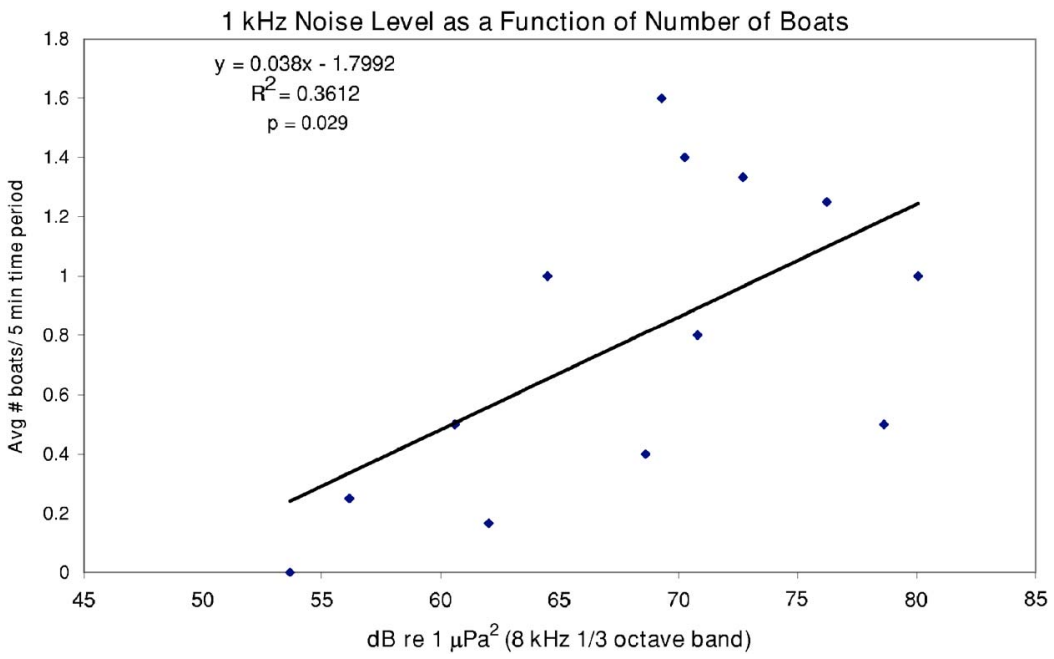

FIG. 6. (Color online) The $1 \mathrm{kHz}$ noise level as a function of boat presence in grassbeds during the morning hours.

grassbed is attenuated quickly compared to low-use sites. This also happens to be the range of most efficient sound propagation inside the grassbed habitat, and the dominant frequencies of manatee vocalizations (Nowacek et al., 2003). For frequencies below $2 \mathrm{kHz}$, transmission loss is not correlated with usage, but low frequency noise is, especially during the morning hours. Ultimately, the grassbeds that manatees selected were those that were most quiet due to lower noise below $1 \mathrm{kHz}$ and higher transmission loss above $2 \mathrm{kHz}$. The selection of dredged habitats was not correlated with either noise level or transmission loss, but the dredged habitats used most often by manatees were in close proximity to high-use grassbeds.

The next logical question is what feature is more influential in driving the manatee grassbed usage, noise or habitat quality? Analysis of the seagrass coverage and species composition indicated no correlation between quality and grassbed usage (Miksis-Olds and Miller, 2006). This suggests that noise and associated transmission loss characteristics may play a more dominant role in habitat selection, compared to the limited grassbed quality parameters investigated. This finding contributes to the interpretation of manatee habitat selection and presents a need for clear-cut hypotheses to be experimentally tested in the field. For example, will increasing noise in a high-use grassbed alter use over the course of a week, month, or year? Will decreasing noise in a low-use area increase grassbed use? These questions need to be answered for effective conservation management, for they will be instrumental in directing future management plans.

Time of day also has an effect on how manatees are using their habitat. High-use areas have less low frequency noise at a time when overall noise levels are significantly increasing throughout the bay during the daily night-tomorning transition. It is during this transition period that boat use also increases. There is a concentrated increase of boat use at daybreak, possibly associated with fisherman going out to fish. No concentrated return was observed in the afternoon, as return times appeared widespread possibly due to weather, fishing success, etc. Grassbed usage was negatively correlated with the concentrated boat presence in the morning hours. This suggests that morning boat presence and its associated noise may play a dominant role in grassbed usage on a daily time scale. Other factors to consider are tidal cycle, current, and the change of noise level per unit time.

As Sarasota Bay manatees predominantly use grassbeds to feed (Koelsch, 1997), it can be extrapolated that the presence of boats in the morning and their associated noise may affect manatee foraging behavior. This result is not unique to manatees, as this pattern has also been observed in another endangered species, the wintering bald eagle (Haliaeetus leucocephalus). Eagle numbers on the Skagit River Bald Eagle Natural Area (SRBENA) in northwestern Washington were negatively correlated with daily boat traffic, and feeding declined exponentially with increased boating activity (Stalmaster and Kaider, 1998). However, early morning boat traffic was most disruptive to eagle feeding behavior. Eagles took longer to return to foraging sites during morning disturbances than later in the day.

Masking of important biological signals is yet another impact of rising ambient noise levels and transient sources. On average, grassbeds were $14 \mathrm{~dB}$ louder than dredged habitats. The average level of ambient noise in high and low use grassbeds, as a function of frequency, differed as much as $30 \mathrm{~dB}$. With ambient noise levels reaching over $90 \mathrm{~dB}$ re $1 \mu \mathrm{Pa}$ within multiple one-third octave bands in some grassbeds, it is not unreasonable to estimate that the time at which a manatee first detects a transient noise source, such as an approaching watercraft, could be vastly decreased in high noise conditions. For example, a mere 4-s delay in detection results in the potential loss of approximately $25 \mathrm{~m}$ when swimming at top speed [estimated using a top swim speed of $6.25 \mathrm{~m} / \mathrm{s}$ (Hartman, 1979)].

Masking also reduces the range of effective vocal communication between manatees. Estimates of manatee vocalization source levels range from 106 to $115 \mathrm{~dB}$ root mean square (rms) re $1 \mu \mathrm{Pa}$ at $1 \mathrm{~m}$ (Nowacek et al., 2003; Phillips et al., 2004). In addition, Schevill and Watkins (1965) reported that the vocalizations were not particularly loud, registering only $10-12 \mathrm{~dB}$ above the background noise at 3-4 $\mathrm{m}$ in a vegetation-choked canal. Increases in ambient noise levels on the order of $10-12 \mathrm{~dB}$ are not uncommon, but could have drastic repercussions for the manatee in terms of effective range of communication and the energy required 
to maintain effective communication if they respond to noise by increasing their source level.

\section{ACKNOWLEDGMENTS}

The authors would like to acknowledge the Manatee Research Program at Mote Marine Laboratory for contributing aerial survey information and field interns. Special thanks are also extended to John Reynolds (Mote Marine Laboratory), David Farmer (URI), and Cheryl Wilga (URI). This research was supported by a P.E.O. Scholar Award and National Defense Science and Engineering Graduate Fellowship awarded to Jennifer Miksis. Data were collected on free-ranging animals under the permits issued by the U.S. Federal Fish and Wildlife Service to the Florida Fish and Wildlife Research Institute (FWRI) (MA773494-7) and to Dr. David Mann of the University of South Florida (USF) (MA051709-0).

Albers, V. M. (1965). Underwater Acoustics Handbook-II (The Pennsylvania State U.P., University Park, PA).

Au, W. W. L., and Banks, K. (1998). "The acoustics of the snapping shrimp Synalpheus parneomeris in Kaneohe Bay," J. Acoust. Soc. Am. 103, 4147.

Camp, D. K., Lyons, W. G., and Perkins, T. H. (1998). "Checklists of Selected Marine Invertebrates of Florida," Report FMRI Technical Report TR-3, Florida Department of Environmental Protections.

Etter, P. C. (1996). Underwater Acoustic Modeling (E \& FN SPON, London).

Gannon, J. G., Scolardi, K. M., Reynolds, J. E., III, Koelsch, J. K., and Kessenich, T. J. (2007). "Habitat selection by manatees in Sarasota Bay, Florida," Marine Mammal Sci., 23, 133-143.

Koelsch, J. (1997). "The seasonal occurrence and ecology of Florida manatees (Trichechus manatus latirostris) in coastal waters near Sarasota, FL,' M.S. thesis, University of Southern Florida, Tampa.

Kryter, K. D. (1985). The Effects of Noise on Man, 2nd ed. (Academic, Orlando, FL).
Marine Mammal Commission. (1986). "Habitat protection needs for the subpopulation of West Indian manatees in the Crystal River area of northwest Florida," Document No. PB86-200250 (National Technical Information Service, Silver Springs, MD).

Miksis-Olds, J. L. (2006). "Manatee response to environmental noise," Ph.D. dissertation, University of Rhode Island, Narragansett.

Miksis-Olds, J. L., and Miller, J. H. (2006). "Transmission loss in manatee habitats," J. Acoust. Soc. Am. 120, 2320-2327.

Nowacek, D. P., Casper, B. M., Wells, R. S., Nowacek, S. M., and Mann, D. A. (2003). "Intraspecific and geographic variation of West Indian manatee (Trichechus manatus spp.) vocalizations (L)," J. Acoust. Soc. Am. 114(1), 66-69.

Nowacek, S. M., Nowacek, D. P., Johnson, M. P., Shorter, K. A., Powell, J. A., and Wells, R. S. (2002). "Manatee behavioral responses to vessel approaches: Results of digital acoustic logger tagging of manatees in Belize," Mote Marine Laboratory Technical Report No. 847, Mote Marine Laboratory, Sarasota, FL.

Nystuen, J. (2004). "Using acoustic rain gauges to monitor underwater sound," Workshop on Ocean Ambient Noise Budgets and Long Term Monitoring: Implications for Marine Mammals, Warwick, RI.

Phillips, R., Niezrecki, C., and Beusse, D. O. (2004). "Determination of West Indian manatee vocalization levels and rate," J. Acoust. Soc. Am. 115, 422-428.

Richardson, W., Greene, C., Malme, C., and Thomson, D. (1995). Marine Mammals and Noise (Academic, San Diego, CA).

Schevill, W. E., and Watkins, W. A. (1965). "Underwater calls of Trichechus (Manatee)," Nature (London) 205, 373-374.

Sousa-Lima, R. S., Paglia, A. P., and Da Fonseca, G. A. B. (2002). "Signature information and individual recognition in the isolation calls of the Amazonian manatees, Trichechus inunguis (Mammalia: Sirenia)," Anim. Behav. 63, 301-310.

Stalmaster, M., and Kaider, J. (1998). "Effects of recreational activity on wintering bald eagles," Wildlife Monogr 137, 1-46.

Urick, R. J. (1983). Principles of Underwater Sound (Peninsula, Los Altos, CA.).

Hartman, D. S. (1979). "Ecology and behavior of the manatee (Trichechus manatus) in Florida." American Society of Mammalogists, Special Publication 5 . 